\title{
Do Creatinine Blood Levels Act upon Fatty Acid Metabolites in Human Red Blood Cell Membranes?
}

\author{
Gallo Giuseppe, Martino Guglielmo*
}

\section{Gallo Giuseppe, Martino Guglielmo*}

Department of Biology, Ecology and Earth Sciences, University of Calabria, Rende, ITALY.

\section{Correspondence}

\section{Prof. Guglielmo Martino}

Full Professor, Department of Biology, Ecology and Earth Sciences, University of Calabria, Rende-87030, ITALY.

Phone no: +39984934572

E-mail: gugliemo.martino@unical.it

History

- Submission Date: 10-06-2019;

- Review completed: 27-06-2019;

- Accepted Date: 30-07-2019.

DOI : 10.5530/fra.2019.2.14

Article Available online

http://www.antiox.org

Copyright

(C) 2019 Phcog.Net. This is an openaccess article distributed under the terms of the Creative Commons Attribution 4.0 International license.

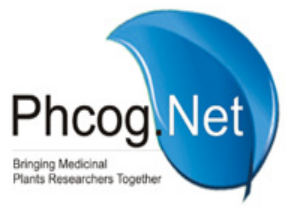

\begin{abstract}
Objectives: The aim of the present research is to correlate creatininemia and uricemia to HNE and MDA levels of Red Blood Cell purified membranes in comparison to those of normal subjects to characterize the effects of oxidative stress. Methods: The studied population consisted of 10 patients with endogenous both hypercreatininemic hyperuricemic and ten normal subjects. The measurement of total proteins in RBC ghosts and HNE and MDA are conducted on blood samples of patients. Results: The obtained data evidence that both creatinine and uric acid levels have influence on the ratio of both MDA/protein and HNE/protein content on RBC ghosts, demonstrating their possible protective role against oxidative stress at low concentrations in blood and oxidizing power at higher concentrations. Conclusion: The displayed results in this study suggest that at low concentrations of creatinine and uric acid there is oxidative stress in human erythrocyte membrane, but if creatinine and uric acid have slowed down to sufficient limits there is also oxidative stress, as demonstrated by MDA and HNE levels; only if the concentration of these two substances overwhelms a threshold.

Key words: Oxidative stress, Creatininemia, Uricemia, Red blood cell, Cytoplasmic membranes.
\end{abstract}

\section{INTRODUCTION}

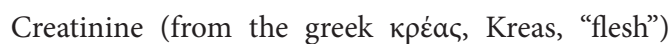
$(\mathrm{Cr})$ is an intermediate of energy metabolism synthesized by the liver about ( $1 \mathrm{~g} /$ day) from arginine, S-adenosyl methionine and glycine (Figure 1) and is used in mammalian muscles to regenerate ATP during the first seconds of muscle contraction. A wide number of research articles indicate that $\mathrm{Cr}$ is capable of exerting multiple, non-energy related, effects on several and relevant cellular targets. Among these effects, the antioxidant activity of $\mathrm{Cr}$ emerges as an additional mechanism. ${ }^{1}$ The human organism is able to sequestrate creatinine up to $0.3 \mathrm{~g}$ per $\mathrm{kg}$ of body weight.

When creatinine products of animal origin are absorbed, they have phosphorylation on nitrogen that occurs in phosphocreatine from muscle cells. ${ }^{2}$ It is normally sought in its breakdown product in the urine and blood (serum creatinine), creatinine and it is also an index of renal function. It was subsequently used in medical therapy and is a supplement used by athletes, especially in anaerobic disciplines, such as bodybuilding, weightlifting and powerlifting.

In 2002, Lawler JM et al. demonstrated that Cr acts as a direct scavenger of radical species in an acellular setting. ${ }^{1} \mathrm{Cr}$ is naturally produced and stored in muscles where it is involved in energy generation. It is widely used, especially by athletes, ${ }^{3}$ as a staple supplement to improve physical performance. Recent reports showed that $\mathrm{Cr}$ displays antioxidant activity which could explain its beneficial cellular effects. Some authors. ${ }^{3}$ (Figure 2), have evaluated the ability of $\mathrm{Cr}$ to protect human erythrocytes and lymphocytes against oxidative damage. Erythrocytes were challenged with model oxidants, 2, 2'-azobis (2-amidinopropane) dihydrochloride (AAPH) and hydrogen peroxide $\left(\mathrm{H}_{2} \mathrm{O}_{2}\right)$ both in the presence and absence of Cr. Incubation of erythrocytes with oxidants alone increased hemolysis, met-hemoglobin levels, lipid peroxidation ${ }^{4}$ and protein carbonyl content. This was accompanied by decrease in glutathione cellular levels. Antioxidant enzymes and antioxidant power of the cell were compromised while the activity of membrane bound scavenger enzymes were lowered. ${ }^{3}$ In a recent paper ${ }^{5}$ authors demonstrated that hypertriglyceridemia affects Red Blood Cell membrane oxidative status (increase of [MDA] and [HNE] to membrane protein ratio) is increased by high levels of blood cholesterol, but selectively by hypertriglyceridemia. ${ }^{5,6}$

It is known that $\mathrm{Cr}$ protects the erythrocytes by attenuating the AAPH and $\mathrm{H}_{2} \mathrm{O}_{2}$ induced alterations. ${ }^{6}$ This protective effect was confirmed by electron microscopic analysis which showed that oxidant-induced cell damage was attenuated by Cre. Thus, Cre can function as a blood antioxidant, protecting cells from oxidative damage, genotoxicity and can potentially increase their lifespan. 
Rutkowski P et al. $2007^{7}$ studied the relationship between the novel uremic toxins and oxidative stress markers in cell membrane.

According to Buranakarl C et al. $2009^{8}$ on blood oxidative stress markers, the U-MDA/Cr (urinary MDA to creatinine ratio) had a positive relationship with (fractional excretion of sodium): $\mathrm{FE}_{\mathrm{Na}}(\mathrm{U}-\mathrm{MDA} / \mathrm{Cre}=$ $\left.\left(0.958 \times \mathrm{FE}_{\mathrm{Na}}\right)+6.668 ; \mathrm{r}=0.555 ; n=35 ; P<0.001\right)$ and control of blood pressure. UP:Cre ratio (urine protein: creatinine ratio) $(\mathrm{U}-\mathrm{MDA} / \mathrm{Cre}=$ $(0.410 \times \mathrm{UPC})+13.272 ; \mathrm{r}=0.298 ; n=46 ; P<0.05)(5)$ is also positively related with urine mechanisms controlling blood pressure (Figure 2).

Uric acid is an organic molecule of natural origin. Urate is formed as a byproduct (Figure 3) in living mammalian organisms higher in purine metabolism. It belongs to the group of oxypurines and is formed from a pyrimidine ring $(\alpha)$ condensed with an imidazole ring $(\beta)$. Hyperuricemia plasma concentration is defined and, in the human being, is normally between 2.5 and $7.0 \mathrm{mg} / \mathrm{dL}$ in male and between 1.5 and $6.0 \mathrm{mg} / \mathrm{dL}$ in female. ${ }^{9,10}$ The limit of $7.0 \mathrm{mg} / \mathrm{dL}$ is important, because at that concentration, the blood saturation occurs and the precipitation of crystals typical of gout becomes possible. ${ }^{9,11}$ At higher values this status is called hyperuricemia and at lower levels hypouricemia.

Uric acid, despite being a major antioxidant in the human plasma, both correlates and predicts development of obesity, hypertension and cardiovascular disease, conditions associated with oxidative stress. ${ }^{12}$ While one explanation for this paradox could be that a rise in uric acid concentration represents an attempted protective response by the host, we review the evidence that uric acid may function either as an antioxidant (primarily in plasma) or pro-oxidant (primarily within the cell). We suggest that it is the pro-oxidative effect of uric acid, see Figure 4, that occurs in cardiovascular disease and may have a contributory role in the pathogenesis of this condition.

According to the researches of Ching B et al. $2015^{13}$ the serum MDA (Mean \pm SEM $24.4 \pm 2.38$ vs $7.9 \pm 0.28 \mathrm{nmol} / \mathrm{ml}$ ) is well related to serum uric acid levels $(7.2 \pm 0.25 \mathrm{vs} 3.9 \pm 0.14 \mathrm{mg} / \mathrm{dl})$, that were significantly increased in preeclampsia cases compared to the normotensive pregnant women respectively and a weak positive correlation between blood uric acid and MDA was observed in preeclampsia cases. $(r=0.065, p<0.734)^{14}$ in thirty pregnant subjects.

The aim of the present research is to correlate creatininemia and uricemia to HNE and MDA concentrations of purified Red Blood Cell membranes in comparison to those of normal subjects to characterize the effects of oxidative stress.

\section{MATERIALS AND METHODS}

\section{Samples}

The studied population consisted of 10 patients with endogenous hypercreatininemia and hyperuricemia, respectively ten pathological and ten normal subjects who were recruited from the Health Center of the University of Calabria, Italy. All patients followed traditional Mediterranean local diet. The study is according to the Ethics law (Law No. 3 of January 11, 2018 of Italy) and all participants provided written informed consent upon entry into the study.

\section{Blood samples}

After fasting, blood is sampled in ethylenediaminetetraacetic acid (EDTAcoated) tubes, selected to determine uricemia according to Schultz A. "Uric Acid" in Kaplan A.: Cin Chem, Mosby Publischer : Co., St Louis (MS) U.S.A. 1984;1261-6. ${ }^{15}$ and creatininemia according to Burtis A et al. $1999 .{ }^{16}$ Blood samples were spun down at $1,550 \mathrm{~g}$ for $10 \mathrm{~min}$, plasma and leukocyte layers are removed and the packed RBC layer is used for the subsequent assays.
RBCs layer is washed three times in PBS isotonic buffer to discard RBC fragments. The integer RBCs are lysed in $5 \mathrm{mM}$ hypotonic phosphate buffer $\mathrm{pH} \mathrm{8,} \mathrm{containing} 100 \mathrm{mM}$ sodium oxalate (to complex interfering metal cations) and PMSF (phenylmethylsulphonyl fluoride) upto $0.03 \mathrm{mM}$, followed by $70 \mathrm{~min}$. centrifugation at $5,000 \mathrm{~g}$ at $5^{\circ} \mathrm{C} .{ }^{17}$ The RBCs ghost sediments are re-suspended by swirling while adding back sufficient fresh hypotonic phosphate buffer to reconstitute the starting volume. The ratio of erythrocyte volume to washing solution volume is $1 / 40$. Subsequent to haemolysing the ghosts were washed at least 3 times by sedimenting in a swinging-bucket rotor $\left(5,000 \mathrm{~g}\right.$ for $\left.70 \mathrm{~min} 5^{\circ} \mathrm{C}\right)$, till free of hemoglobin. Aliquots should be taken for sample replicates, as well as for protein determination. $200 \mu \mathrm{L}$ portions are required for use in protein, MDA and HNE assays. The protein concentration in the homogenate is determined by Biuret method. ${ }^{18}$ It is recommended that $0.2 \mathrm{~mL}$ of a homogenate, containing about $15-60 \mathrm{mg} / \mathrm{mL}$ of protein, to be assayed for initial studies in previously untested biological samples. The supernatant should be kept on ice prior to analyze or, if not analyzed immediately after preparation, frozen at $-70^{\circ} \mathrm{C}$ for longer storage. ${ }^{15}$

\section{Assay of total proteins in RBCs ghosts}

The principle of Biuret method 18 is based on the reaction of the peptide bonds of proteins with $\mathrm{Cu}^{2+}$ ions. In alkaline solution, the formation of an indigo colored complex: the intensity of the color is directly proportional to the protein concentration if the metal is complexed by EDTA. The used standard is BSA (bovine serum albumin fraction V of Cohn) from Sigma-Aldrich. Procedure: Samples are prepared in plugged tubes that are shaken at $37^{\circ} \mathrm{C}$ and after $45 \mathrm{~min}$ the absorbance is read for each sample at $540 \mathrm{~nm}$ on Shimadzu UV 2100 spectrophotometer.

\section{Spectrophotometric analysis of free HNE \\ Assay Procedure for MDA and MDA + HNE}

All reagents are from Sigma-Aldrich (Saint Louis, Missouri, USA). The standards [HNE standard: (E)-4-Hydroxynonenal ( $\mathrm{I} k \mathrm{~B}$ inhibitor) is from Enzo life Sciences] are prepared in clean glass test tubes or polypropylene microcentrifuge tubes. Preferably, standards should be run in triplicate. Add $200 \mu \mathrm{L}$ of each sample to a clean either glass or polypropylene test tube. Unknowns should be run in triplicate. Add $650 \mu \mathrm{L}$ of diluted $\mathrm{N}$-methyl-2-phenylindole reagent (Enzo Life Sciences, NY, USA). Mix gently by vortexing the sample. Add either $150 \mu \mathrm{L}$ concentrated (12 N) $\mathrm{HCl}$ or $(95 \%)$ methansulfonic acid reagent. Stopper and mix well each tube. Incubate at $45^{\circ} \mathrm{C}$ for $60 \mathrm{~min}$. Centrifuge turbid samples (e.g. 15,000 $\mathrm{x} g$ for $10 \mathrm{~min}$ at room temperature in Sigma tabletop microcentrifuge) to obtain a clear supernatant. Transfer by pipet the clear supernatant to a cuvette. Measure the absorbance at $586 \mathrm{~nm}$ on Shimadzu UV $2100 \mathrm{spec}-$ trophotometer. ${ }^{20}$

\section{Statistical analysis}

For statistical analysis one-way ANOVA and Bonferroni post hoc test are used. Results are given as mean \pm standard error on the mean of at least ten independent determinations.

\section{RESULTS}

The increase of MDA and HNE levels represent the elevated activities of oxidative stress in human body. It can be seen from Figures 5 and 7 that the increase of protein concentration in the membrane of the blood samples is associated with the rise of MDA and HNE levels.

From the ratio between either MDA levels $(\mu \mathrm{M})$ or HNE levels and $\mathrm{RBC}$ membrane proteins (g/l), we deduced the following results on the basis of Figures 6 and 8 in which we have divided samples into 3 groups according to their blood ROS levels. 


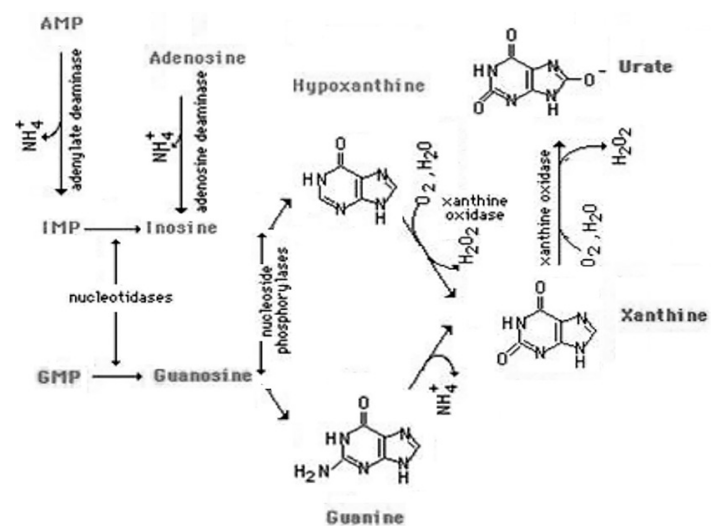

Figure 1: Urate synthesis. In the first step adenosine monophosphate and adenosine produces inosine from which guanosine is synthesized. Guanine is formed both from guanosine and hypoxanthine. Hypoxanthine and guanine give places to xanthine that produces urate and hydrogen peroxide.

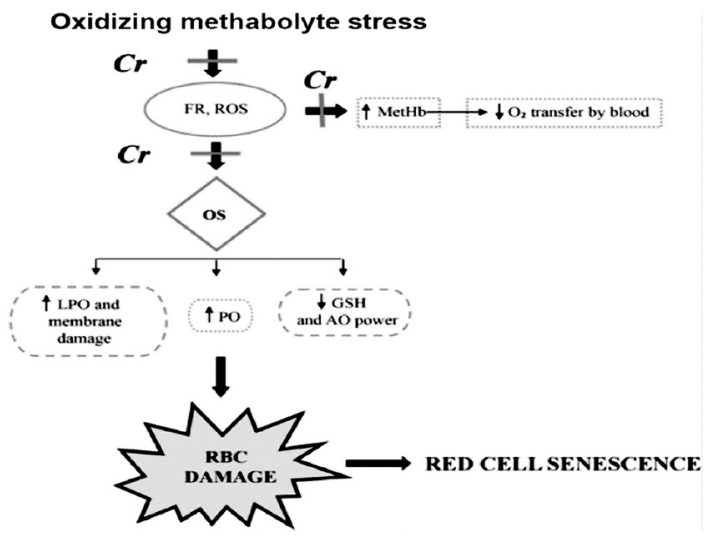

Figure 2: Creatinine biosynthesis. In the first step Glycine and Arginine react to form Guanido acetic acid; this reaction takes place in the kidney. In the second step (liver), methylation of guanido acetic acid takes place to form Methyl guanido acid (creatinine). Creatinine is reversibly phosphorylated to creatinine-P by creatinine kinase. Creatinine phosphate is a high energy compound. Creatinine is produced by the loss of water from creatine phosphate.

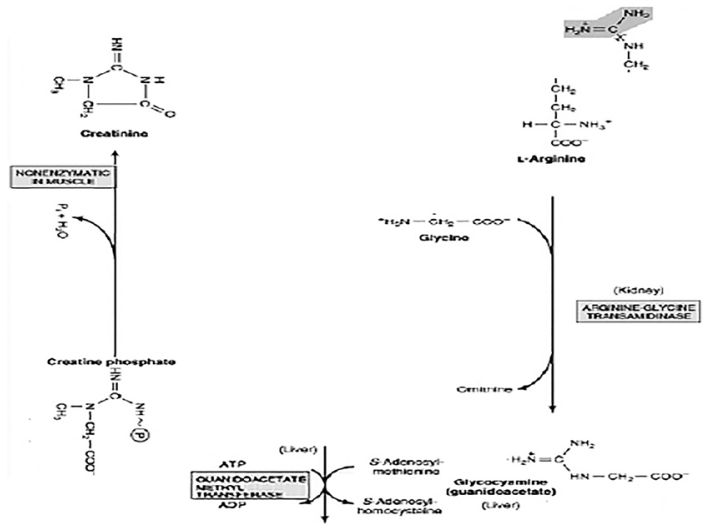

Figure 3: Pathways used by creatinine to induce oxidative stress in eukaryotic cells as modified by present paper Authors.3 LPO Lipoperoxidase. PO Peroxidation. GSH reduced glutathione. AOP antioxidant power.

According to this kind of grouping, we can observe that both uric acid and creatinine levels have influence on the ratio either of MDA/protein or $\mathrm{HNE}$ /protein contents in $\mathrm{RBC}$ membranes, demonstrating their pro-

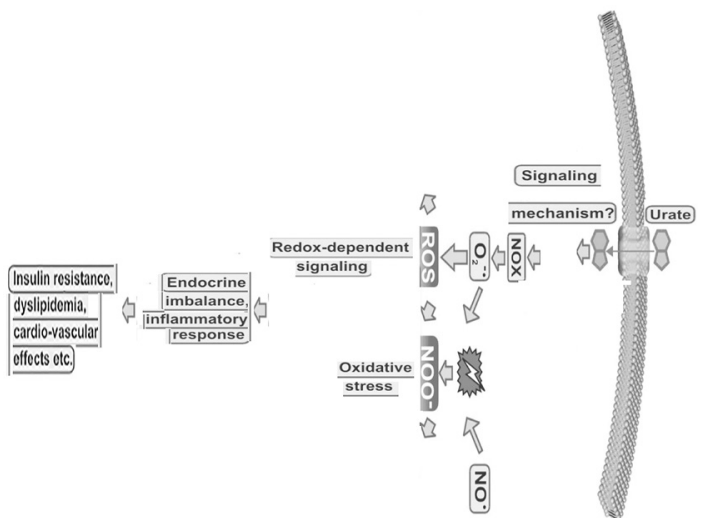

Figure 4: A model for urate-induced oxidative stress in adipocyte as modified by present paper Authors. ${ }^{12}$

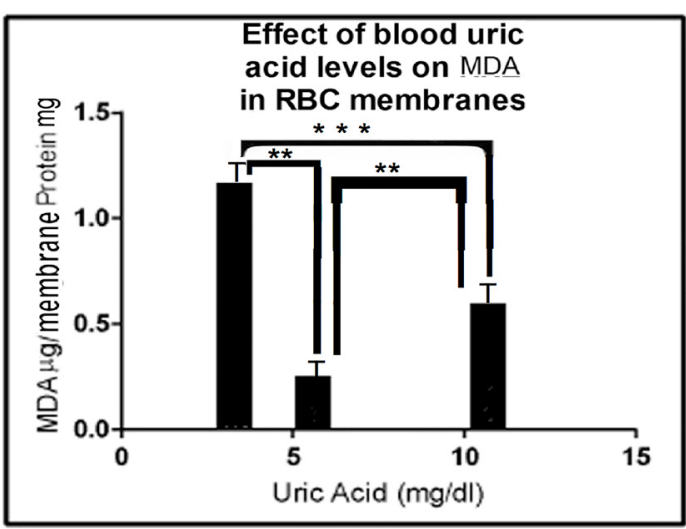

Figure 5: Effect of blood uric acid levels on RBC membrane MDA. Each result is the main plus/minus standard error on the mean of ten independent experiments. Results are evaluated by one-way ANOVA and Bonferroni post-hoc test according to Graphpad Prism 5.0.* $p<0.05,{ }^{* *} p<0.01$ and ${ }^{* *} p<0.001$.

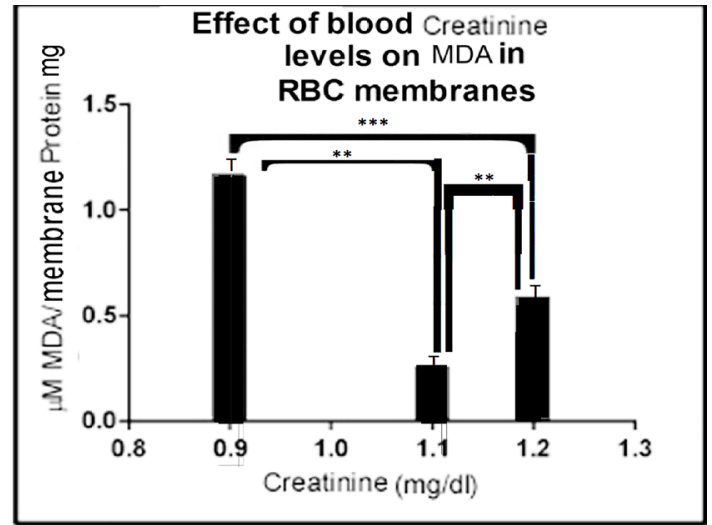

Figure 6: Effect of blood creatinine levels on RBC membrane MDA. Each result is the mean plus/minus standard error on the main of ten independent experiments. Results are evaluated by one-way ANOVA and Bonferroni post-hoc test according to Graphpad Prism 5.0. ${ }^{*} p<0.05 p<0.05,{ }^{* *} p<0.01$ and ${ }^{* * *} p<0.001$.

tective role against oxidative stress at low concentrations (lower than $5 \mathrm{mg} / \mathrm{dL}$, for uric acid) and slight oxidizing power at high concentrations (higher than $1.1 \mathrm{mg} / \mathrm{dL}$, for creatinine), as previously evaluated 


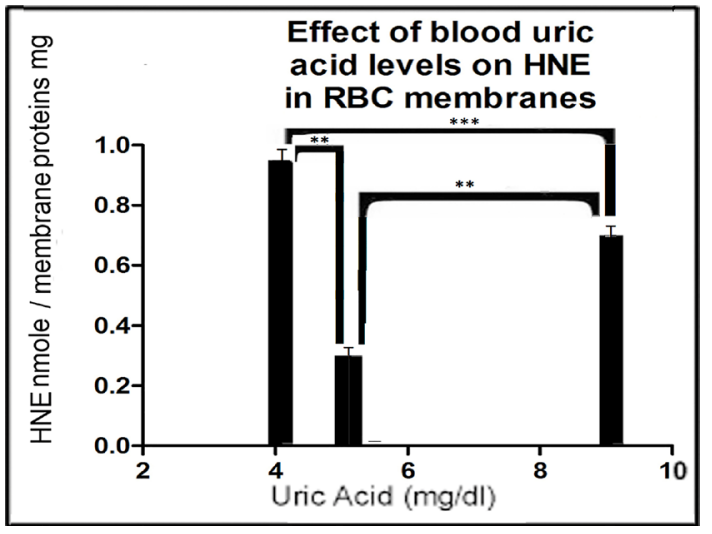

Figure 7: Effect of blood uric acid levels on RBC membrane HNE. Each result is the mean plus/minus standard error on the main of ten independent experiments. Results are evaluated by one-way ANOVA and Bonferroni post-hoc test according to GraphPad Prism 5.0. ${ }^{*} p<0.05,{ }^{* *} p<0.01$ and ${ }^{* * *} p<0.001$.

by Qasim N and Mahmood R $2015^{3}$ and even more powerful oxidant (HNE) could act similarly. In each plot, "a valley" was observed. In this valley, it is seen that there is a dramatically drop in $\mu$ mole concentration of MDA per mg of RBC proteins which signifies low oxidative stress activity. Thus, it suggests that if the concentration of creatinine and uric acid is within medium range of uric acid concentration, each of these substances would strongly express their protective role toward oxidative stress.

In Figures 5-8 one can observe that the recovery of the curve is smooth and starts from the proximal area of Sample knot, suggesting that at this point both Creatinine and uric acid gradually loss their protective abilities as their concentration in the red blood cell membranes increase.

\section{DISCUSSION}

The described results confirm the observation on MDA levels are similar for the action of uric acid and creatinine on ROS levels with almost parallel patterns. ${ }^{7,8,10}$ An hypothetic explanation for this paradox could be that a rise in uric acid concentration represents an attempted protective response by the host. ${ }^{12}$ Probably HNE data in the same experimental conditions should parallel the similar effects of ROS on the oxidation of longer chain lipids in human RBC membranes. The relationship between oxidation of long chain fatty acids and the concentration of both uric acid and creatinine blood levels according to their paradoxical action on oxidation of this kind of RBC constituents probably are attributable to multiple mechanisms of interaction of several constituents of ROSs mixture generated in human organisms with the molecular structures of RBC membranes as carbonylated proteins. This hypothesis shall be investigated in further research also on other structural components of membrane. At present, we have only data on total RBC membrane proteins.

\section{CONCLUSION}

The data from this research suggest that nitrogen metabolism, mainly creatinine, acts upon cellular lipid metabolism, as this chemical in itself is a reductant compound but at high intracellular concentrations it works as an oxidizing product, as described by Qasim $\mathrm{N}$ et al. $2015 .{ }^{3}$ Creatinine metabolism can interact with uric acid excretion by kidneys. Hyperuricemia damages kidneys where creatinine is excreted by humans.

The interaction between concentrations of creatinine and uric acid, that is powerful scavenger of singlet oxygen, slows down the activity of oxi-

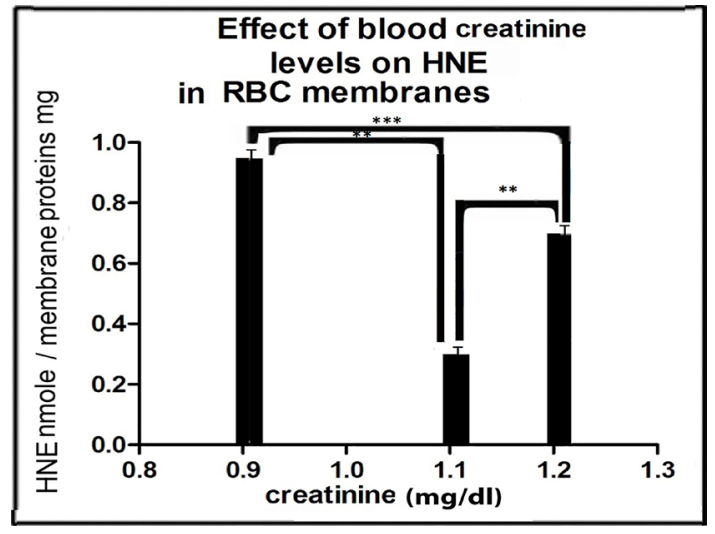

Figure 8: Effect of blood creatinine levels on RBC membrane HNE. Each result is the mean plus/minus standard error on the main of ten independent experiments. Results are evaluated by one way ANOVA and Bonferroni post-hoc test according to GraphPad Prism 5.0. ${ }^{*} p<0.05,{ }^{* *} p<0.01$ and ${ }^{* *} p<0.001$.

dative stress in human erythrocyte membranes. The contemporaneous modulation of both creatinine and uric acid metabolism and their anatomical and functional consequences could modulate MDA and HNE levels. Only if the concentration of these 2 substances overcomes thresholds, they will begin to express their harmful both oxidative and reductive activities. ${ }^{3}$ Lawler JM et al. (2002) ${ }^{1}$ were the first authors to test the hypothesis that $\mathrm{Cr}$ was acting as a radical scavenger using a well-controlled acellular experimental setting. This study showed that $\mathrm{Cr}$ - unlike Cr phosphate $(\mathrm{CrP})$-was capable of scavenging charged radicals such as the 2,2'-Azino-bis (3-ethylbenzothiazoline-6-sulfonic acid radical.

However, because of the limitation of the study, which was based on a limited number of samples, the results are a hint for future studies. As to further studies on this subject, one should consider also targets as age, gender, health conditions and exercise intensity, also expanding the sample pool in order to increase the possibility of plotting a smooth and significant curve that demonstrates the relationships of HNE to Protein levels ratios to $\mathrm{RBC}$ membrane proteins in comparison with the levels of all related indexes (such as blood uric acid and creatinine). Further research could verify this working hypotheses.

\section{ACKNOWLEDGEMENT}

Authors thank Professor Domenico Sturino for his help in mother language revision of manuscript of this review.

\section{Funding}

Source of Support: Ex 60 \% from Ministry of University and Public education.

\section{Informed Consent}

All patients gave informed consent.

\section{CONFLICT OF INTEREST}

Authors declare no conflict of interest.

\section{ABBREVIATIONS}

ATP: Adenosina trifosfato; AAPH: 2'-azobis (2-amidinopropane) dihydrochloride; $\mathrm{H}_{2} \mathrm{O}_{2}$ : Hydrogen peroxide; MDA: Malondialdehyde; HNE: 4-hydroxy-2-nonenal; U-MDA/Cr: Urinary MDA to creatinine ratio; $\mathrm{FE}_{\mathrm{Na}}$ : Fractional excretion of sodium; UP: Cre ratio: Urine protein: creatinine ratio; EDTA: Ethylenediaminetetraacetic acid; RBC: Red blood 
cell; PMSF: Phenylmethylsulphonyl fluoride; BSA: Bovine serum albumin; CrP: Cr phosphate.

\section{REFERENCES}

1. Lawler JM, Barnes WS, Wu G, Song W, Demaree S. Direct antioxidant properties of creatinine. Biochem Biophys Res Commun. 2002;290(1):47-52.

2. Nelson DL, Cox M. In chapter 22: Lehninger Principles of Biochemistry, IV edition, W. H. Freeman Publisher, New York (NY) U.S.A. 2005.

3. Qasim N, Mahmood R. Diminution of Oxidative Damage to Human Erythrocytes and Lymphocytes by Creatinine: Possible Role of Creatinine in Blood. PLoS One. 2015;10(11):e0141975.

4. Mufidah M, Ermina P, Gemini A, Marianti AM, Lukman M, Rusdi M, et al. Lipid Peroxidation Inhibitory Activity in vitro of Mezzetia parvi-flora Becc. Wood Bark Polar Extract. Pharmacogn J. 2017;9(2):171-5.

5. Gallo G, Martino G. In vitro action of 2.2'azobis2 amidinopropan dihydrochloride, red wine polyphenols, resveratrol and catechin on anion permeability for chloride in human red blood cell. Free Radicals and Antioxidants. 2014;4(2):13-7.

6. Gallo G, Bruno R, Taranto A, Martino G. Are Polyunsaturated Fatty Acid Me tabolites, the Protective Effect of 4-hydroxytyrosol on Human Red Blood Cell Membranes and Oxidative Damage (4-hydroxyalkenals) Compatible in Hypertriglyceridemic Patients?. Pharmacogn Mag. 2017:13(Suppl 3):S561-6.

7. Rutkowski P, Stominska EM, Szołkiewicz M, Aleksandrowicz E, Smolenski RT, Wotyniec $\mathrm{W}$, et al. Relationship between uremic toxins and oxidative stress in patients with chronic renal failure. Scand J Urol Nephrol. 2007;41(3):243-8.

8. Buranakarl C, Trisiriroj M, Pondeenana S, Tungjitpeanpong T, Jarutakanon P, Penchome $\mathrm{R}$, et al. Relationships between oxidative stress markers and red blood cell characteristics in renal azotemic dogs. Res Vet Sci. 2009;86(2):309-13.

9. Ronco C, Rodeghiero F. Hyperuricemic Syndromes: Pathophysiology and Therapy. Karger Medical and Scientific Publishers. Basel. 2005.
10. Onyesom I. Synergistic effect of alcohol and fructose administration on blood urate and biochemical indices of insulin resistance in albino rabbits. Indian J Med Res. 2006;124(6):715-7.

11. Heinig M, Johnson RJ. Role of uric acid in hypertension, renal disease and metabolic syndrome. Cleve Clin J Med. 2006;73(12):1059-64.

12. Sautin YY, Johnson RJ. Uric acid the oxidant-antioxidant paradox. Nucleosides Nucleotides Nucleic Acids. 2008;27(6-7):608-19.

13. Chung BH, Kang SH, Hwang HS, Choi BS, Park CW, Kim YS, et al. Clinical significance of early-onset hyperuricemia in renal transplant recipients. Nephron Clin Pract. 2011;117(3):c276-83.

14. Sharmila KE, Venkata RB, Sowjanya A, Saseekala JN. Correlation between malondialdehyde (MDA) and uric acid levels in preeclampsia. Int J Res Med Sci. 2015;3(6):1443-5.

15. Schultz A. "Uric acid". Clin Chem, Mosby Publisher: Co., St Louis. (MIS) U.S.A. 1984;1261-6.

16. Burtis CA, Ashwood ER. In Tietz Textbook of Clinical Chemistry, $3^{\text {rd }}$ ed, Philadephia (Pen), U.S.A. 1999.

17. Giuseppe G, Guglielmo M, Carino A. Spinning, oxidative damage and hemolysis in athletes. Free Radicals and Antioxidants. 2013;3(2):61-6.

18. Datta SP, Leberman R, Rabin BR, et al. The chelation of metal ions by dipeptides and related substances. Trans Faraday Soc. 1959;55:214151.

19. GerardMonnier D, Erdelmeier I, Regnard K, MozeHenry N, Yadan JC, Chaudiere J. Reactions of 1 methyl2phenylindole with malondialdehyde and 4hydroxyalkenals. Analytical applications to a colorimetric assay of lipid peroxidation. Chem Res Toxicol. 1998;11(10):117683

20. Constantin A, Constantinescu E, Dumitrescu M, Calin A, Popov D. Effects of ageing on carbonyl stress and antioxidant defense in RBCs of obese Type 2 diabetic patients. J Cell Mol Med. 2005;9(3):68391.

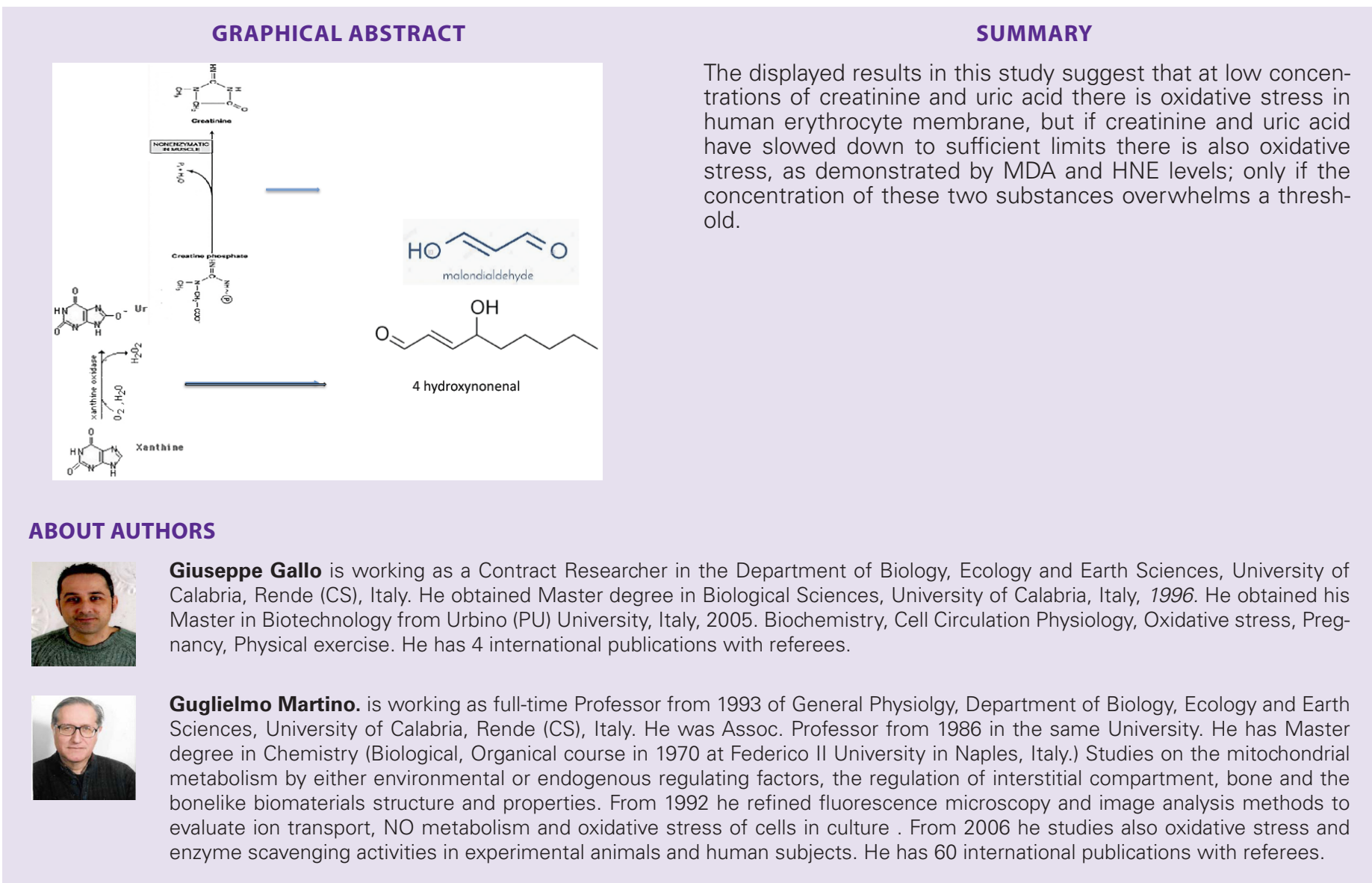

Cite this article: Giuseppe G, Guglielmo M. Do Creatinine Blood Levels Act upon Fatty Acid Metabolites in Human Red Blood Cell Membranes?. Free Radicals and Antioxidants. 2019;9(2):78-82. 